\title{
NuA4 and SAGA acetyltransferase complexes cooperate for repair of DNA breaks by homologous recombination
}

\author{
Xue Cheng $₫$, Valérie Côté, Jacques Côté ${ }^{*}$ *
}

St-Patrick Research Group in Basic Oncology, Laval University Cancer Research Center, Oncology Division of $\mathrm{CHU}$ de Québec-Université Laval Research Center, Quebec City, Canada

* jacques.cote@ crhdq.ulaval.ca

\section{Abstract}

Chromatin modifying complexes play important yet not fully defined roles in DNA repair processes. The essential NuA4 histone acetyltransferase (HAT) complex is recruited to double-strand break (DSB) sites and spreads along with DNA end resection. As predicted,

\section{G openaccess}

Citation: Cheng X, Côté V, Côté J (2021) NuA4 and SAGA acetyltransferase complexes cooperate for repair of DNA breaks by homologous recombination. PLOS Genet 17(7): e1009459. https://doi.org/10.1371/journal.pgen.1009459

Editor: Sue Jinks-Robertson, Duke University, UNITED STATES

Received: February 27, 2021

Accepted: June 21, 2021

Published: July 6, 2021

Peer Review History: PLOS recognizes the benefits of transparency in the peer review process; therefore, we enable the publication of all of the content of peer review and author responses alongside final, published articles. The editorial history of this article is available here: https://doi.org/10.1371/journal.pgen.1009459

Copyright: @ 2021 Cheng et al. This is an open access article distributed under the terms of the Creative Commons Attribution License, which permits unrestricted use, distribution, and reproduction in any medium, provided the original author and source are credited.

Data Availability Statement: All relevant data are within the manuscript and its Supporting Information files.

Funding: This work was supported by a grant from the Canadian Institutes of Health Research (cihr-
NuA4 acetylates surrounding nucleosomes upon DSB induction and defects in its activity correlate with altered DNA end resection and Rad51 recombinase recruitment. Importantly, we show that NuA4 is also recruited to the donor sequence during recombination along with increased $\mathrm{H} 4$ acetylation, indicating a direct role during strand invasion/D-loop formation after resection. We found that NuA4 cooperates locally with another HAT, the SAGA complex, during DSB repair as their combined action is essential for DNA end resection to occur. This cooperation of NuA4 and SAGA is required for recruitment of ATP-dependent chromatin remodelers, targeted acetylation of repair factors and homologous recombination. Our work reveals a multifaceted and conserved cooperation mechanism between acetyltransferase complexes to allow repair of DNA breaks by homologous recombination.

\section{Author summary}

DNA double-strand breaks (DSBs) are among the most dangerous types of DNA lesions as they can produce genomic instability that leads to cancer and genetic diseases. It is therefore crucial to understand the precise molecular mechanisms used by cells to detect and repair this type of damages. Homologous recombination using sister chromatid as template is the most accurate pathway to repair these breaks but has to occur within the context of the DNA compacted structure in chromosomes. Here, we show that two enzymes, NuA4 and SAGA, that acetylate the structural components of chromosomes in the vicinity of the DNA breaks are together essential for recombination-mediated repair to occur. We found that they are recruited at an early step after damage detection and their action allows subsequent remodeling of local structural organisation by other enzymes, providing DNA access to the recombination machinery. These results highlight the cooperation of enzymes for a same goal, providing robustness in the repair process as only the loss of both leads to major defects. 
irsc.gc.ca)(FDN-143314) to J.C. X.C. was supported by doctoral studentships from Fonds de Recherche du Québec-Santé (www.frqs.gouv.qc. ca), Fondation du CHU de Québec-Université Laval (fondationduchudequebec.org) and Centre de Recherche sur le Cancer de l'Université Laval (crc. ulaval.ca). J.C. holds the Canada Research Chair in Chromatin Biology and Molecular Epigenetics (www.chairs-chaires.gc.ca). The funders had no role in study design, data collection and analysis, decision to publish, or preparation of the manuscript.

Competing interests: The authors have declared that no competing interests exist.

\section{Introduction}

DNA double-strand breaks (DSBs) are one of the most detrimental types of DNA lesions that need to be handled properly to preserve genome integrity [1]. DSBs can be repaired by two major pathways, non-homologous end-joining (NHEJ) and homologous recombination (HR), while other types of repair also play important roles [2]. Repair by NHEJ tends to be errorprone due to its template-independent nature whereas repair by HR is mostly error-free [2]. Notably, DSB repair takes place in the context of chromatin. Consistent with this, several studies have gradually delineated the functional interplay between chromatin modifiers/remodelers and critical processes during DNA repair $[3,4]$.

The yeast 13-subunit NuA4 histone acetyltransferase (HAT) complex has been implicated in the repair of DNA breaks [5-9]. Highly conserved during evolution, the main activity of $\mathrm{NuA} 4$ is to acetylate nucleosomal histone $\mathrm{H} 4$ and $\mathrm{H} 2 \mathrm{~A}(\mathrm{Z} / \mathrm{X})$ through its catalytic subunit KAT5 (Esa1/Tip60), the sole HAT protein essential for cell viability in Saccharomyces cerevisiae [10,11]. Initial evidence for NuA4 involvement in repair came from yeast experiments showing that cells with mutations of NuA4 subunits or its lysine targets on the $\mathrm{H} 4$ tail are sensitive to DNA-damaging agents, suggesting that $\mathrm{NuA} 4$ and its activity are required for efficient repair $[6,8,12,13]$. Subsequent analysis of NuA4 functions in DSB repair found that it is physically recruited to an endonuclease-induced DSB [6]. This recruitment is performed through a direct interaction with the Mre11-Rad50-Xrs2 (MRX) complex and leads to spreading of $\mathrm{NuA} 4$ along with DNA end resection $[5,14]$. Local acetylation of chromatin has been argued to help recruitment of ATP-dependent remodelers near the break site [6,15]. NuA4 has also been implicated in DNA damage tolerance, post-replicative and nucleotide excision repairs [1618], the latter also involving Gcn5/SAGA, another major HAT activity [19]. In human cells, $\mathrm{NuA} 4$ (a.k.a. the TIP60 complex) regulates DNA damage signalling and counteracts 53BP1 to favour repair by HR instead of NHEJ [20-22]. However, the functional consequences of NuA4 recruitment near DSBs in the repair process per se remain to be clearly defined.

In this study, we aimed to define NuA4 function and requirement during the repair of DNA DSB. Using a conditional mutant and a rapid depletion approach in the context of integrated DSB-induction system in budding yeast, we found that NuA4 participates in multiple steps during HR but do so through an essential collaboration with another HAT complex, SAGA, regulating chromatin dynamics, DNA end resection and non-histone substrates.

\section{Results}

\section{NuA4-dependent acetylation of chromatin around a DNA break affects end resection}

In order to study NuA4 function in DNA DSB repair, we first used a thermosensitive (ts) mutant of Esal (esa1-L254P) [11] integrated in a well-established system that uses the HO endonuclease under the control of the GAL promoter to produce a single inducible DSB at the MAT locus in the yeast genome (pGAL-HO, hml $/ h m r \Delta$ ) [23]. Although the non-permissive temperature compromised HO cleavage efficiency (S1 A Fig) potentially due to NuA4 involvement in transcription [10], semi-permissive temperature allows us to partially cripple $\mathrm{NuA} 4$ activity while still effectively generating DSBs in vivo (S1B and S1C Fig). Accordingly, the increase of local $\mathrm{H} 4$ acetylation detected upon DSB formation measured by ChIP-qPCR at different distances from the break (normalised for nucleosome occupancy and compared to no DSB conditions) is lost at semi-permissive temperature (Figs 1A, 1B and S1D). In parallel, we also integrated the anchor-away system [24] into the aforementioned inducible DSB background, aiming to rapidly deplete proteins from the nucleus upon rapamycin treatment while 
A

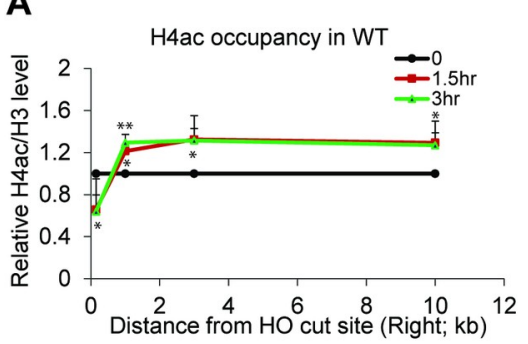

C

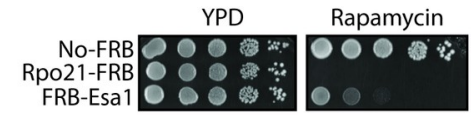

E

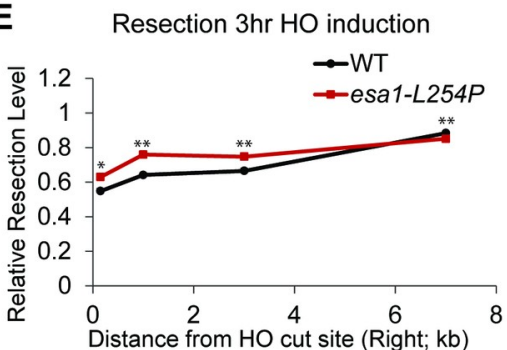

G

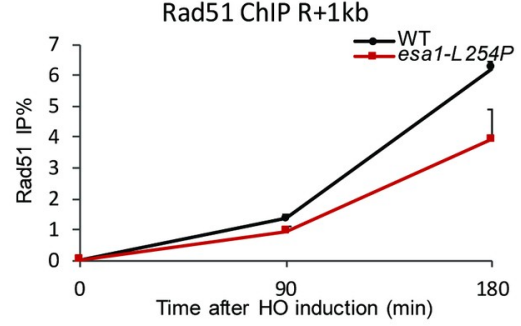

I

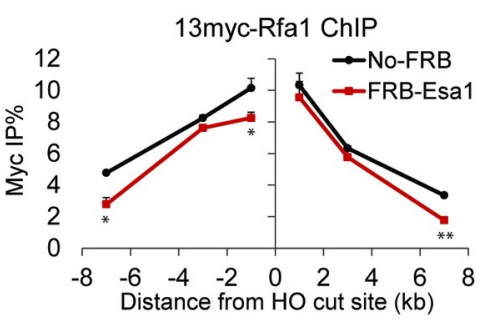

B

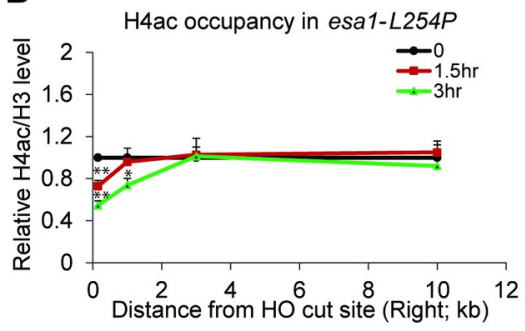

D

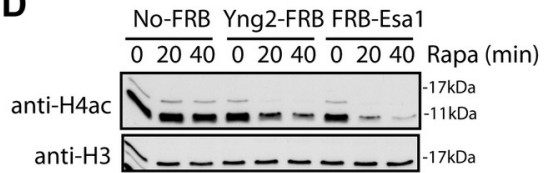

F

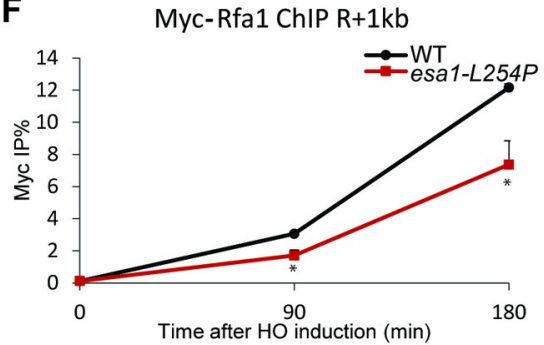

H

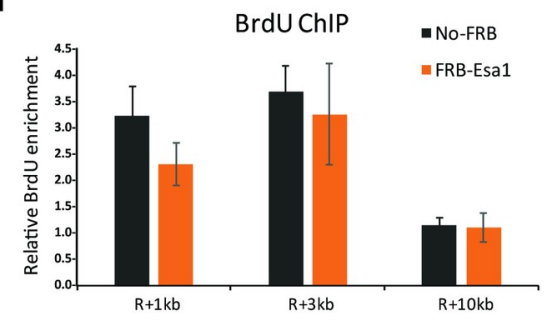

J

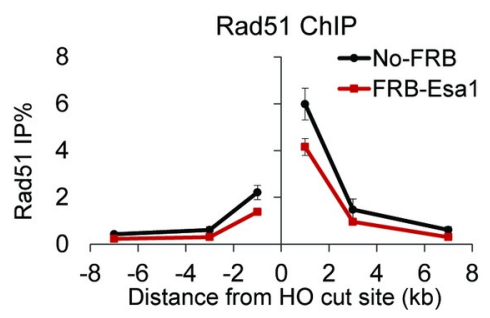

Fig 1. NuA4 is required for $\mathbf{H} 4$ acetylation upon DSB induction and affects resection. A-B) ChIP-qPCR of H4ac signal near the DSB site (H4ac/total $\mathrm{H} 3$ ratio of \%IP/input) in WT and esa1 ts strains during 0, 90 and 180min of galactose induction of $\mathrm{HO}$ nuclease. Values at the different locations near the DSB at time 0 was normalized to 1 , showing the increase of $\mathrm{H} 4$ acetylation upon $\mathrm{HO}$ cut in WT conditions but not in mutant at $32^{\circ} \mathrm{C}$ (error bars are range of biological replicates). C) 10-fold serial dilutions of indicated FRB-tagged strains were spotted on YPD or YPD containing $1 \mu \mathrm{g} / \mathrm{ml}$ rapamycin and grown at $30^{\circ} \mathrm{C}$, showing loss of viability by depletion of Esal and RNA PolII largest subunit for comparison (Rpo21). D) WB of WCE from indicated strains treated with $1 \mu \mathrm{g} / \mathrm{ml}$ rapamycin for 0,20 or 40min, showing loss of H4 acetylation by depletion of Esa1 and Yng2, another subunit of NuA4 (not used further as it affects Gal induction). E) Resection assay of WT and esa1-L254P cells after $3 \mathrm{hr}$ of galactose induction at $32^{\circ} \mathrm{C}$. DNA content around the break was measured by qPCR with genomic DNA and normalized on uncut locus (interV), showing higher level of DNA remaining near the DSB in mutant cells. F-G) ChIP-qPCR assay of 13myc-Rfal (F) and Rad51 (G) next to the DSB site in WT and esa1-L254P after 0, 90 and $180 \mathrm{~min}$ of $\mathrm{HO}$ induction at $32^{\circ} \mathrm{C}$, showing less accumulation in mutant conditions. H) ChIP-qPCR assay of BrdU in No-FRB and FRB-Esal strains after 3 hr of galactose induction in presence of rapamycin, showing slightly less exposed ssDNA near the break after Esal depletion. BrdU enrichment was normalized on control locus (interV). I-J) ChIP-qPCR assay of 13myc-Rfa1 (I) and Rad51 (J) in 
No-FRB and FRB-Esal cells after $3 \mathrm{hr}$ galactose induction in presence of rapamycin, showing less accumulation in Esa1-depleted conditions. Error bars in ChIP-qPCR represent range from biological replicates. (Statistical analyses were performed by one-tailed t-test: $\left.{ }^{*} \mathrm{p}<0.05,{ }^{* *} \mathrm{p}<0.01,{ }^{* * *} \mathrm{p}<0.001\right)$.

https://doi.org/10.1371/journal.pgen.1009459.g001

importantly preserving robust DSB formation. Unlike other depletion approaches that involves degradation of the target protein, this system uses a rapamycin-induced physical interaction with a ribosomal protein to rapidly deplete a protein from the nucleus by forcing its translocation to the cytoplasm [24]. Since C-terminal tagging of Esa1 with FRB leads to a decrease in global acetylation even without rapamycin treatment (S1E Fig, potentially due to the importance of an intact C-terminus), we created N-terminal FRB-tagging of endogenous Esal, keeping it under control of its own promoter. Upon rapamycin treatment, FRB-Esa1 cells show dramatic defect in growth (Fig 1C) and a rapid decrease in global $\mathrm{H} 4$ acetylation level (Fig 1D), demonstrating that anchor-away of FRB-Esal is potent and efficient (i.e. validating Esal depletion from the nucleus). Notably, the cutting efficiency of the $\mathrm{HO}$ endonuclease under these Esal anchor-away conditions is comparable to the respective WT (No-FRB) while $\mathrm{H} 4$ acetylation near the break is crippled (S1F-S1I Fig). Interestingly, both systems indicate that the domain of NuA4-dependent increased $\mathrm{H} 4$ acetylation upon DSB formation is larger than the extent of detected NuA4 binding/spreading in these conditions (3-5kb, see [5]), suggesting longer-range action in the tri-dimensional space, similar to what has been reported for chromatin remodelers [25].

Since histone acetylation can directly attenuate DNA-histone interactions and can be recognized by bromodomain-containing ATP-dependent chromatin remodelers [10,15], its NuA4dependent increase near the DSB is expected to affect nucleosome stability [9](S1J Fig) and downstream events like HR-linked DNA end resection process. Nucleosomes represent physical barriers to resection, thus defects in nucleosome displacement generally impact repair of the break [3,26-30]. Accordingly, in the ts mutant, we detect a small but significant decrease of DNA end resection near the break site which is shown by the mutant having more DNA left near the break (red line) compared to WT conditions (black line) (resection is measured by a lower qPCR signal at different locations near the DSB due to the loss of one DNA strand) (Fig $1 \mathrm{E}$ ). The mutant conditions also show decreased single-strand DNA (ssDNA) binding RPA (Rfa1 subunit) and Rad51 recombinase recruitment measured by ChIP-qPCR (Fig $1 \mathrm{~F}$ and $1 G)$. These results are also confirmed using the anchor-away system with ssDNA detection using BrdU-labeling followed by anti-BrdU ChIP-qPCR in non-denaturing conditions as well as RPA/Rad51 ChIP-qPCR (Figs $1 \mathrm{H}-1 \mathrm{~J}$ and $\mathrm{S} 1 \mathrm{~K}$ and S1L).

A functional link between NuA4 and resection is further supported by strong genetic interactions detected between a viable anchor-away NuA4 mutant (Eaf1-FRB) and key resection factors in the presence of DNA damage, namely early acting/MRX-linked endonuclease Sae2, as well as longer and parallel acting exonuclease Exo1 and helicase Sgs1 [31](Fig 2A-2D). Accordingly, NuA4 does not affect DSB repair by resection-independent end-joining (S2A Fig). On the other hand, there is no increased DNA damage sensitivity with deletion of the Fun30 ATP-dependent chromatin remodeler that has been linked to DNA end resection [28], suggesting an epistatic relationship (Figs 2E and S2B). If DNA damage sensitivities observed in NuA4 mutant cells are solely due to the impaired resection, one would expect boosting resection activity would rescue NuA4 mutant sensitivity to DNA damage. Overexpression of long-range resection factor Exo1 has been shown to rescue the FUN30 deletion [28]. However, we did not observe suppression of the DNA damage sensitivity of esa1 mutant cells when overexpressing Exo1 (Fig 2F). This suggests that NuA4 role in the repair of DNA breaks is not limited to resection. While decreased recruitment of the Rad51 recombinase in Esa1-depleted 


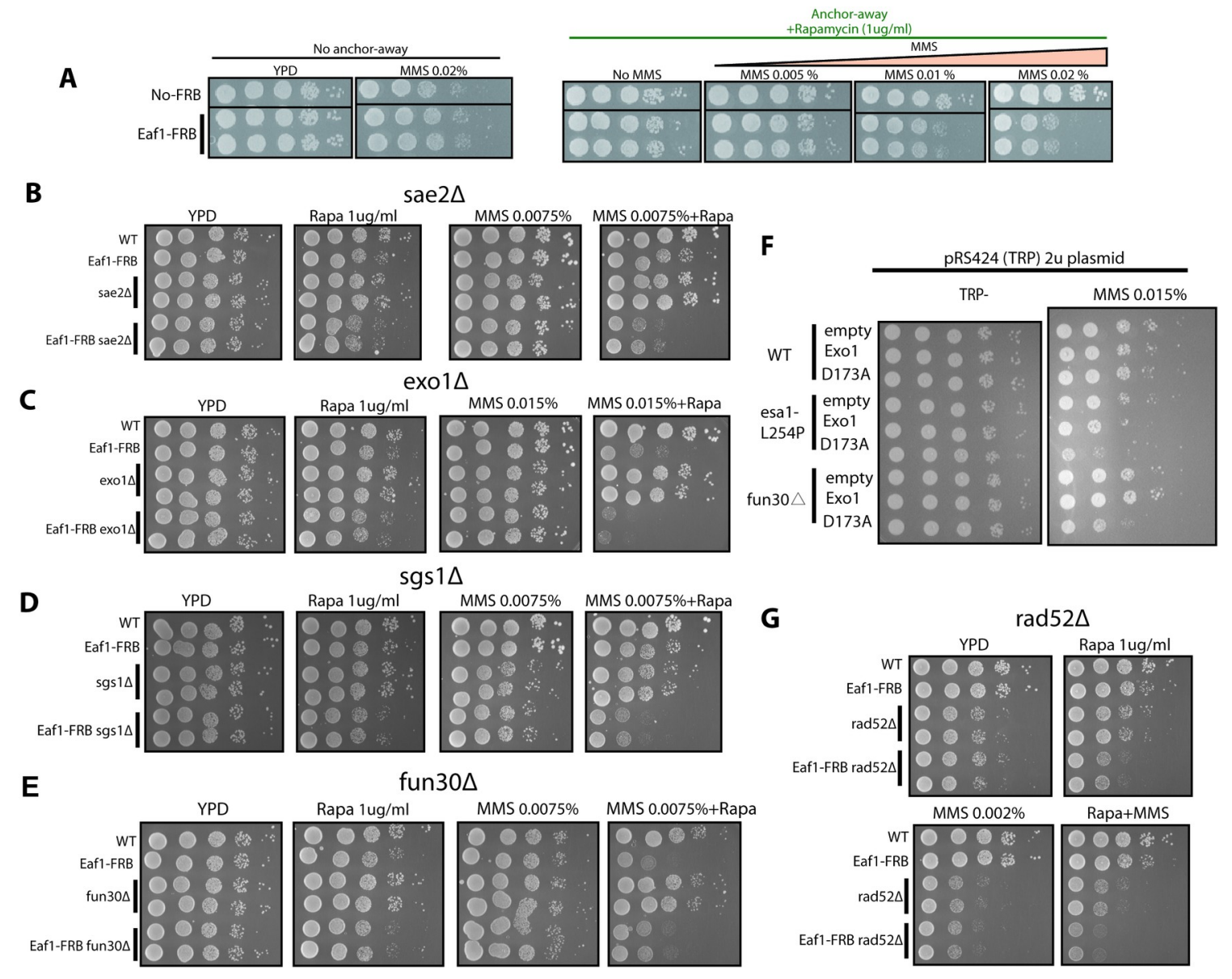

Fig 2. NuA4 shows genetic interaction with resection and recombination factors. A-E, G) 10 -fold serial dilutions of indicated strains were spotted on solid medium without or with $1 \mu \mathrm{g} / \mathrm{ml}$ rapamycin supplemented without or with indicated amounts of MMS and grown at $30^{\circ} \mathrm{C}$. Another subunit of NuA4 was used with the FRB tag, scaffold subunit Eaf1[12], as its depletion does not affect cell viability on rich media (A). Genetic interaction (sickness/growth defect in presence of DNA damage induced by MMS) is seen with genes for resection factors Sae2 (B), Exo1 (C), Sgs1 (D) but not Fun30 (E), and with recombination factor Rad52 (G). F) DNA damage sensitivity of esa1 ts cells cannot be overcome by over-expression of potent resection factor Exo1. Spot assays as above with the indicated strains. The fun 30 deleted strain is used as control as it was shown to be rescued by Exol expression but not its catalytic mutant form (D173A) [28].

https://doi.org/10.1371/journal.pgen.1009459.g002

cells (Fig $1 \mathrm{G}$ and $1 \mathrm{~J}$ ) is most likely linked to reduced resection/RPA loading, genetic interaction between $\mathrm{NuA} 4$ and recombination factor Rad52 (Fig 2G) suggests that NuA4 may also play a role in the recombination step after resection.

\section{NuA4 plays a role in strand invasion at the homologous donor sequence}

To progress through HR, the Rad51 recombinase replaces RPA on the resected ssDNA and this Rad51 filament performs homology search, ultimately invading the homologous donor sequence to form a structure termed D-loop. Importantly, this donor sequence is also covered with nucleosomes that require disruption. To investigate whether NuA4 can directly participate in the later steps of HR such as recombination/D-loop formation, we again took advantage of the inducible DSB system in this case carrying an intact donor sequence (HML/HMR) in the genome (Fig 3A). After break induction followed by removal of the $\mathrm{HO}$ endonuclease, we observed by ChIP the presence of both Rad51 and NuA4 at the invading strand, as 

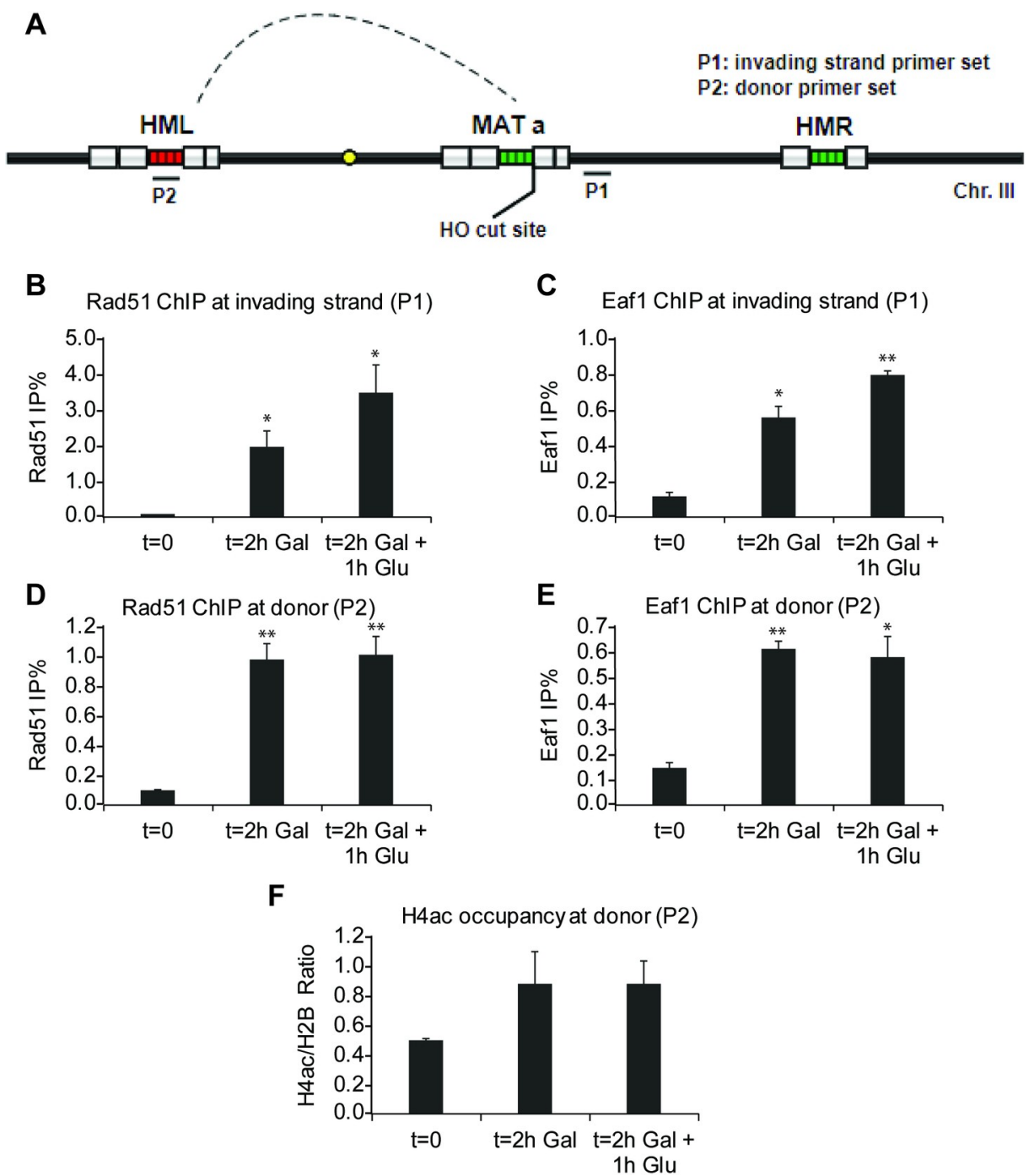

Fig 3. NuA4 functions at the donor homologous sequence during HR, implicating chromatin acetylation during D-loop formation. A) Schematic representation of HR donor strain genome arrangement and primer positions for ChIP-qPCR. B-E) ChIP-qPCR assay (\% of Ip/input) of Rad51 (B, D) and Eaf1 (C, E) in HR donor strain after 0, 2hr galactose induction or $2 \mathrm{hr}$ galactose induction followed $1 \mathrm{hr}$ glucose $(2 \%)$ treatment to block $\mathrm{HO}$ nuclease expression. Rad51 and NuA4 are clearly recruited at both the invading strand from the HO cut and and at the donor sequence during HR. Error bars represent range from biological duplicates. F) ChIP-qPCR of NuA4-dependent H4 acetylation at the donor sequence (H4ac/total $\mathrm{H} 2 \mathrm{~B}$ ratio of \% IP/input), showing a clear increase during HR. Error bars represent standard error from biological triplicates. (Statistical analyses were performed by one-tailed t-test: ${ }^{*} \mathrm{p}<0.05,{ }^{* *} \mathrm{p}<0.01$, ${ }^{* * *} \mathrm{p}<0.001$; and multiple comparisons significance was also confirmed by one-way ANOVA followed by Tukey test).

https://doi.org/10.1371/journal.pgen.1009459.g003

previously reported (Figs 3B and 2C) [5,32]. Importantly, the association of Rad51 was also detected using primers specific for the donor sequence, confirming the formation of D-loop (Fig 3D). Interestingly, the presence of NuA4 was also found at the donor locus (Fig 3E) (using an antibody for Eaf1, the only subunit unique to NuA4 [12]). Importantly, a concomitant increase of $\mathrm{H} 4$ acetylation is also detected at the donor sequence, albeit just short of statistical significance $(\mathrm{p}=0.06)$ (Fig $3 \mathrm{~F})$. These results provide the first evidence that physically links NuA4 and its activity to formation of the D-loop, suggesting a role in modulating chromatin structure at the donor sequence to allow recombination. 
To measure the importance of $\mathrm{NuA} 4$ in the recombination process in vivo, we used a yeast HR reporter assay in which an uncuttable MAT donor sequence (MAT-inc) is integrated in the genome of the inducible HO-DSB system. In this system, cells with DSBs repaired by HR will become resistant to $\mathrm{HO}$ cleavage, thus growing on the solid medium containing galactose [33]. Surprisingly, using both the esa1-L254P mutant at semi-permissive temperature and the viable anchor-away NuA4 mutant (Eaf1-FRB), we did not observe a significant defect in homologous recombination using this assay (S2C and S2D Fig). While this was also reported for another NuA4 mutant [13], one explanation may be that NuA4 itself is not essential for the repair of endonuclease-induced "clean-end" DSBs, similar to what has been reported for Sae2 (CtIP) and Mre11 nuclease [34]. Another possibility is the relatively small effect on end resection seen in NuA4 mutants not being sufficient to affect $\mathrm{HR}$ in this assay over the long time of growth on plates. It could also be due to functional redundancy or cooperativity with another chromatin modifier (see below).

\section{Combined recruitment of NuA4 and SAGA acetyltransferases is essential for DNA end resection}

In a previous ChIP experiment coupled to mass spectrometry to identify proteins linked to DNA end resection (RPA) after HO-DSB formation, we could detect NuA4 components along with repair proteins [5]. Interestingly, beside ATP-dependent chromatin remodelers, a subunit of the SAGA histone acetyltransferase complex was also detected (Fig 4A). In transcription regulation, NuA4 has been shown to collaborate with SAGA, which targets $\mathrm{H} 3$ and $\mathrm{H} 2 \mathrm{~B}$ tails in nucleosomes through its catalytic subunit Gen5 [35-37]. Both NuA4 and SAGA have also been shown to acetylate non-histone substrates, some linked to the DNA repair process [5,7,38-41]. NuA4 and SAGA share the large ATM/ATR-related Tral subunit which is implicated in their recruitment to gene promoters by activators [42]. Since NuA4 is recruited by the MRX complex potentially through a direct interaction with Tra1 [5], we asked if the SAGA complex is also recruited to DNA breaks and collaborates with $\mathrm{NuA} 4$, as in gene regulation. Indeed, using SAGA scaffold subunit Spt7 [43], we observe clear recruitment of SAGA by ChIP after DSB induction, covering 3-5kb next to the break (Fig 4B). Importantly, this recruitment of SAGA is lost in $x r s 2 \Delta$ mutant cells, suggesting that it also involves MRX. To test whether this similar mode of recruitment leads to a functional collaboration between $\mathrm{NuA} 4$ and SAGA during DSB repair by homologous recombination, we examined resection levels in Esal and/or Gen5 anchor-away conditions by measuring the exposure of ssDNA using BrdU and RPA binding by ChIP-qPCR (Figs 4C, 4D and S3A-S3D for controls). Although anchoraway of a single HAT shows little difference compared to No-FRB cells, a complete loss in ssDNA exposure is observed when both HATs are depleted (Fig 4C), correlated by a similar complete loss of RPA binding (Fig 4D), supporting an essential combined role of NuA4 and SAGA during DNA end resection. As the ssDNA generated by resection can activate DNA damage checkpoint through the Mec1-dependent pathway [44], we reasoned that the crippled resection in double anchor-away conditions should also impact checkpoint activation. Consistent with our hypothesis, checkpoint activation is highly defective in double anchor-away conditions as shown by measuring Rad53 phosphorylation (Fig 4E). It has been argued that NuA4 and SAGA acetyltransferase activities can independently affect the recruitment of the SWI/ SNF chromatin remodeler near DSBs through bromodomain-acetylated histones interactions [15]. Since the loss of acetylation correlates with increased nucleosome occupancy near the DSB in our Esa1/Gcn5-double depleted background (S3E and S3F Fig), we investigated defects in the recruitment of chromatin remodelers. Recruitment of the SWI/SNF complex is indeed greatly affected by the combined loss of NuA4 and SAGA (Fig 4F and 4G), but we also 
A

\begin{tabular}{cccc} 
Complex & Subunit & - DSB & + DSB \\
\hline SAGA & Sgf29 & 0 & 3 \\
\hline \multirow{2}{*}{ INO80/SWR1 } & Rvb2 & 4 & 10 \\
& Rvb1 & 4 & 9 \\
\hline \multirow{2}{*}{ SWI/SNF } & Snf2 & 1 & 8 \\
& Swi3 & 3 & 10 \\
\hline \multirow{4}{*}{ RSC } & Rsc3 & 1 & 3 \\
& Rsc9 & 2 & 6 \\
& Rsc7 & 2 & 5 \\
& Rsc4 & 3 & 4 \\
\hline
\end{tabular}

C

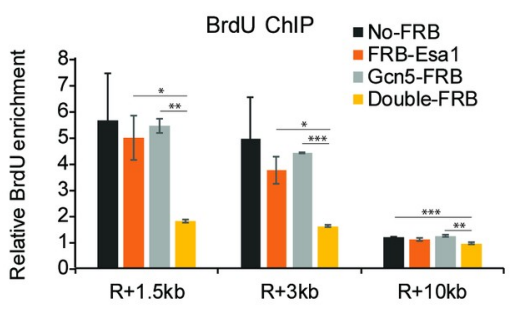

E

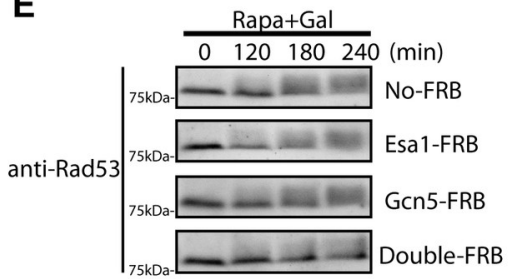

G

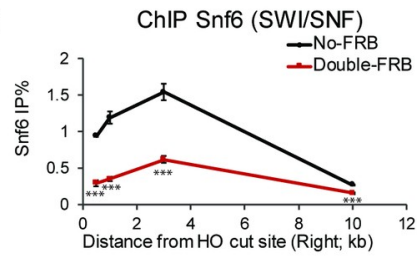

I

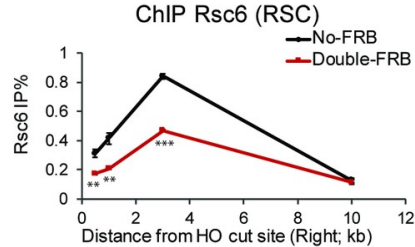

B

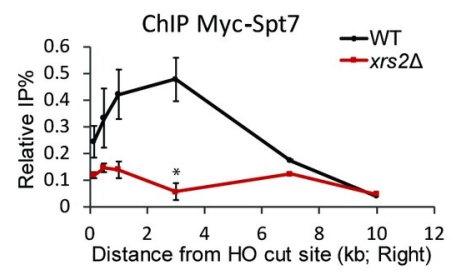

D

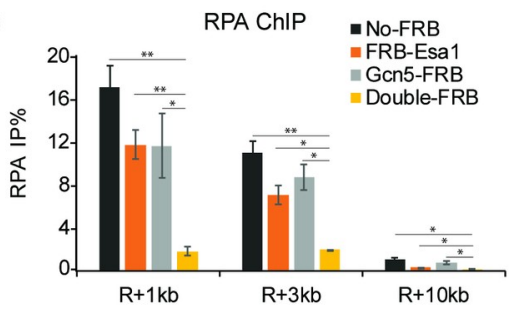

F

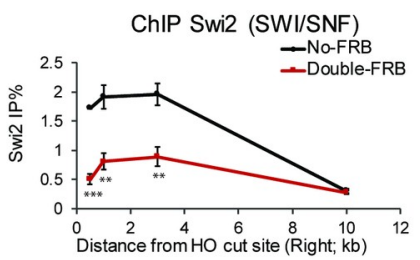

H

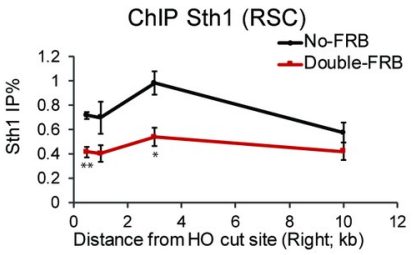

$\mathbf{J}$

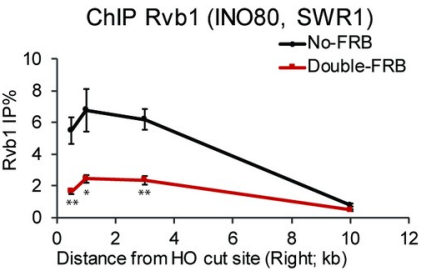

Fig 4. Essential collaboration of NuA4 and SAGA HAT complexes at DSBs to allow DNA end resection and recruitment of ATP-dependent chromatin remodelers. A) List of protein components of chromatin remodeling/ modifying complexes and number of total peptides detected in ChIP of Flag-Rfal followed by MS analysis from cells after 0 or $90 \mathrm{~min}$ of $\mathrm{HO}$ induction [5], showing increased association of remodelers but also a component of the SAGA HAT complex. B) ChIP-qPCR assay of Myc-Spt7 (SAGA scaffold subunit) in WT and $x r s 2 \Delta$ cells after $3 \mathrm{hr}$ of HO induction with galactose. \% of IP/input is shown at different locations near the DSB after subtraction of the signal in untagged strain. C) ChIP-qPCR assay of BrdU in indicated FRB-tagged strains after $3 \mathrm{hr}$ galactose induction in the presence of rapamycin to measure ssDNA production (as in Fig $1 \mathrm{H}$ ). BrdU enrichment was normalized on control locus (inter V). D) ChIP-qPCR as in (B) but measuring resection through anti-RPA, showing again full loss of resection when Esal and Gcn5 are both depleted. E) DNA damage checkpoint activation measured by Western blotting of Rad53 (Santa cruz, sc-6749) from whole cell extracts after 0, 2, 3, 4hr of galactose induction in presence of rapamycin, showing slower migrating signal upon activation by DNA damage, which is lost after depletion of both Esa1 and Gcn5. F-J) Recruitment of ATP-dependent chromatin remodeling complexes at locations near the HO DSB as measured by ChIP-qPCR with specific antibodies after $3 \mathrm{hr}$ of galactose induction in presence of rapamycin. The Esa1/Gcn5 double depletion shows clear defects in recruitment of these factors. Error bars represent range from biological duplicates. (Statistical analyses were performed by one-tailed t-test: ${ }^{*} \mathrm{p}<0.05,{ }^{* *} \mathrm{p}<0.01,{ }^{* * *} \mathrm{p}<0.001$; and multiple comparisons significance for $\mathrm{C}$ and $\mathrm{D}$ was also confirmed by one-way ANOVA followed by Tukey test).

https://doi.org/10.1371/journal.pgen.1009459.g004 
see defects in the recruitment of the essential remodeling complex RSC which contains multiple bromodomains (Fig $4 \mathrm{H}$ and $4 \mathrm{I}$ ), as well as the Rvb-containing remodeling complexes (Ino80/Swr1)(Fig 4J).

\section{NuA4 cooperates with SAGA to allow HR-mediated repair of DSBs in eukaryotes}

Using qPCR to measure repair by HR in the inducible DSB system coupled to an uncuttable donor sequence (as above), a strong defect in HR efficiency is also observed in Esa1/Gcn5 double anchor-away conditions (Fig 5A and 5B). Depletion of the potential SAGA/NuA4 common recruiting interface Tral by anchor-away also shows reduction in RPA and Rad51 association on each side of the DSB, albeit not as much as the double Esa1/Gcn5 depletion, suggesting other means of recruitment (S4A-S4D Fig). Altogether, these results indicate that NuA4 collaborates with SAGA to promote repair of DNA breaks by HR, at least in part through combined acetylation of chromatin (histone $\mathrm{H} 4 / \mathrm{H} 2 \mathrm{~A} / \mathrm{H} 2 \mathrm{~B} / \mathrm{H} 3$ tails) that promotes nucleosome removal/disruption by chromatin remodelers.

We next asked whether NuA4 and SAGA could also collaborate in targeting non-histone substrates implicated in DNA repair, such as key resection/ssDNA-binding factor RPA, which has been shown to be a substrate of NuA4 in yeast DSB repair [5] and Gcn5 in mammalian nucleotide excision repair [39,41]. Acetylation of yeast RPA by NuA4 on multiple lysine residues has been shown to affect its binding to single-strand DNA produced during resection [5]. Using Acetyl-lysine immunoprecipitation (IP) followed by RPA western blot (WB), we observe decreased RPA signal in Esa1 or Gcn5 anchor-away conditions (Fig 5C). Importantly, RPA signal is further strongly decreased in the double anchor-away condition, indicating that RPA acetylation depends on both NuA4 and SAGA in vivo.

While mammalian NuA4, the TIP60 complex, has been implicated in break repair by HR for many years [20-22], the role of mammalian SAGA came to light more recently [45]. The well-conserved nature of both complexes led us to test whether they also function together to promote HR-mediated break repair in human cells. We used the DR-GFP HR reporter assay in U2OS cells by measuring GFP-positive cells after I-SceI induction of a DSB (as in [20]). While single siRNA-mediated knock-down (KD) of either Tip60 or Gcn5 shows mild HR defect, double KD led to a strong defect in HR efficiency (Fig 5D). KD of the Gcn5 paralog PCAF did not show this effect but a significant alteration of the cell cycle profile makes it difficult to interpret (S5A and S5B Fig). Overall, our results support an essential conserved cooperation between two major HAT complexes, NuA4 and SAGA, to promote repair of DNA breaks by homologous recombination, through acetylation of both chromatin and non-histone substrates.

\section{Discussion}

In this study, we discovered that the NuA4 complex is involved not only in the resection but also at the recombination step of repair by HR. The role of NuA4-dependent acetylation of histone $\mathrm{H} 4$ and $\mathrm{H} 2 \mathrm{~A}$ in a large domain surrounding the DNA break was expected to be linked to nucleosome destabilization to allow end resection but it is now also linked to strand invasion/ D-loop formation at the donor sequence (Fig 3). NuA4 mutants have been shown to affect recruitment of ATP-dependent chromatin remodelers INO80/SWR1 and bromodomain-containing SWI/SNF to the HO-induced break [6,14], as well as the RSC complex to stabilize GAG-repeats during replication [17]. The Gen5 HAT has also been shown to affect SWI/SNF recruitment at the break [15] and, recently, to collaborate with MRX at stalled replication forks, playing a role in resection of nascent DNA [46]. We now show that the Gcn5-containing 
A

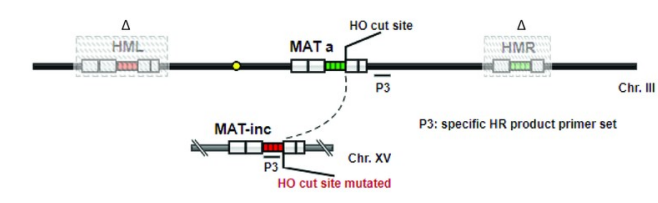

B

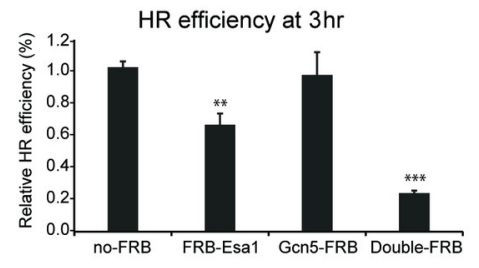

C

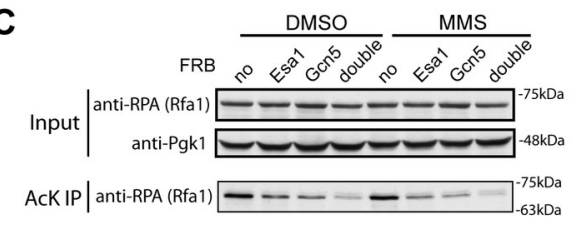

D

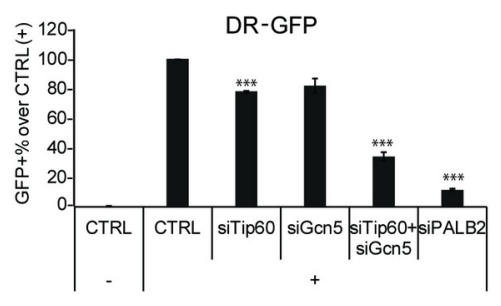

E
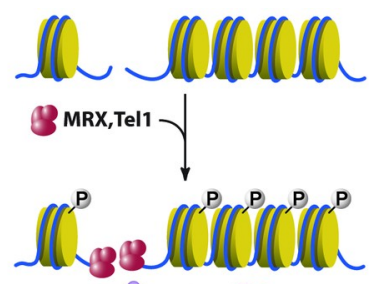

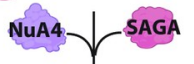

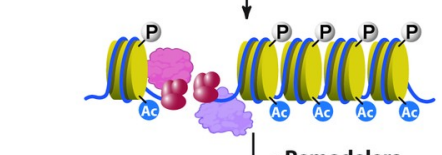

Remodelers

Resection machinery RPA

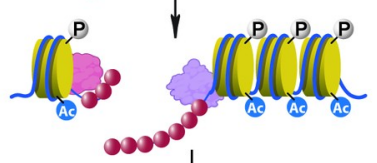

NuA4/SAGA acetylate RPA

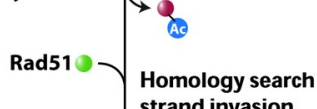

strand invasion

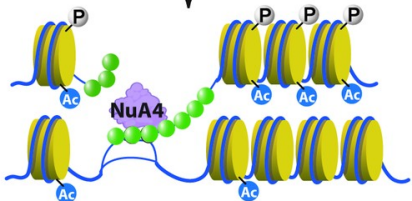

Fig 5. NuA4 and SAGA also cooperate for acetylation of RPA and are together required of DSB repair by HR from yeast to humans. A) Schematic representation of uncuttable-donor (MAT-inc) strain genome arrangement and primer positions to detect repair by HR. B) HR assay by qPCR on genomic DNA with primers shown (A) after $3 \mathrm{hr}$ of $\mathrm{HO}$ induction in presence of rapamycin and normalization on control locus (InterV). Double depletion of Esal and Gcn5 shows strong defect of repair by HR. Error bars represent standard error from three biological replicates. C) Measurement of in vivo RPA acetylation by Western blotting after acetyl-lysine IP from whole cell extracts corresponding to the indicated strains, incubated with rapamycin plus DMSO or MMS (0.05\%) for $3 \mathrm{hr}$. Inputs signals before Kac IP are shown for control as well as Pgk1 for loading and relative molecular weight marker positions. Both Esal and Gcn 5 affect the level of RPA acetylation in the cell. D) HR reporter assay in human U2OS cells containing an inducible I-SceI endonuclease and an integrated DR-GFP reporter. After siRNA transfection, I-SceI DSB induction and repair, cells were subject to fluorescence-activated cell sorting (FACS) analysis for GFP expression (reflecting the level of repair by HR). Results represent the percentage of GFP-positive cells normalized on control siRNA. Double knock-down of Tip60 and hGcn5 shows stronger defect in repair by HR. PALB2 knock-down is shown as positive control. Error bars represent standard error from three biological replicates. E) Model depicting the roles of NuA4 and SAGA HAT complexes for the repair of DNA breaks by homologous recombination. It shows the recruitment to the break by MRX, acetylation of chromatin to allow resection with recruitment of remodelers, followed by acetylation of RPA on resected ssDNA and acetylation of chromatin at the homologous donor sequence during strand invasion. (Statistical analyses were performed by one-tailed t-test: ${ }^{*} \mathrm{p}<0.05,{ }^{* *} \mathrm{p}<0.01,{ }^{* * *} \mathrm{p}<0.001$; and multiple comparisons significance for B and D was also confirmed by one-way ANOVA followed by Tukey test).

https://doi.org/10.1371/journal.pgen.1009459.g005

SAGA complex is recruited to the DNA break in a Xrs2-dependent manner, similar to NuA4. Strikingly, we show that the combined action of the two HAT complexes is essential for DNA end resection to occur after appearance of the DSB, and therefore HR (Figs 4 and 5). Several studies have highlighted the cooperation between NuA4 and SAGA in gene transcription through acetylation of chromatin [35-37]. It has been shown that NuA4- and SAGA-dependent local acetylation of chromatin stimulates the association of ATP-dependent chromatin remodelers SWI/SNF and RSC through an interaction of their bromodomains with acetylated 
histones both at the promoter and during transcription elongation [47-49]. Since SWI/SNF and RSC complexes are also involved in the repair of DSBs [50] and have been recently shown to be essential for nucleosome eviction and DNA end resection [51], it is not surprising that a similar mechanism can occur following NuA4- and SAGA-dependent acetylation of nucleosomes surrounding the damage site, and that loss of both complexes has a most detrimental effect. Since it was proposed that SWI/SNF, RSC and Ino80 function at different steps of the HR process [30,52-54], it will be interesting to investigate whether the HAT complexes are implicated. Moreover, since transcription at DSBs has been recently implicated in the repair process [55-57], it will be also important to determine if NuA4/SAGA-dependent acetylation can drive transcription near DNA breaks. Based on current and previous results, a model for $\mathrm{NuA} 4$ and SAGA function in HR-mediated repair of DSBs is depicted in Fig 5E. It highlights their essential role upstream of chromatin remodelers for DNA end resection and implicates $\mathrm{NuA} 4$ at the later step of strand invasion during HR.

Important questions remain about NuA4 and SAGA involvement/mechanisms in different DNA repair pathways. NuA4-dependent acetylation of RPA has been suggested to destabilize RPA from ssDNA [5]. Our results indicate that NuA4 and SAGA again cooperate in that process, which in turn could favour RPA replacement by the Rad51 recombinase. This is difficult to judge in our system since NuA4 and SAGA are required for resection and therefore RPA loading on the ssDNA. Since RPA antagonizes micro-homology mediated end-joining (MMEJ) [58], it is also possible that NuA4 and SAGA participate in MMEJ repair by regulating RPA dynamics. A study in mammalian cells reported that $\mathrm{p} 400$, a subunit of the TIP60/NuA4 complex, regulates a similar alternative end-joining pathway [59], supporting another possible conserved function in repair pathways.

Moreover, other DNA damage response factors are substrates of HATs, such as Rad50 and Sae2 [40,60]. NHEJ factors are also known to be acetylated, including Ku and Nej1 [61,62]. It will be interesting to determine how NuA4 and SAGA may directly regulate these factors and differentially affect HR and NHEJ pathways. The literature and our data point to an essential role of histone acetyltransferase activities in stimulating DSB repair by the HR pathway, while histone deacetylases have been reported as major facilitators of NHEJ [63]. This highlights an important function of chromatin structure in regulating resection which is the key step in repair pathway selection. Since NuA4 and SAGA are highly conserved during evolution and involved in several human diseases [10,64], it will be of interest to dissect the actions of each HAT, investigate the potential functional redundancy in these acetylation events and elucidate the multifaceted HAT collaboration from yeast to human. The development of HAT inhibitors with greater specificity will allow efficient synthetic lethal screens to target specific cancer types in order to cripple their repair potential during radio- and chemotherapy [65]. Interestingly, Tip60/KAT5 has recently been identified through a CRISPR screen as a key regulator of PARP inhibitor response in BRCA2-deficient cells [66].

\section{Methods}

\section{Yeast strains}

Yeast strains used in this study are listed in S1 Table and were constructed based on conventional PCR-based transformation protocol. Detailed construction information is available upon request. For $\mathrm{N}$-terminal tagging of proteins, 500bp upstream and $500 \mathrm{bp}$ downstream sequence from start codon was inserted in pFA6a-kanMX6 plasmid [67] after the kanMX6 cassette using Gibson assembly cloning (NEB, E2611). FRB tag [24] was then inserted after the start codon by using Gibson assembly cloning and used as template for PCR. Cells were transformed with PCR product using forward primer (40bp before start codon 
+ GAATTCGAGCTCGTTTAAAC) and reverse primer ( 20bp reverse complement sequence before $+500 \mathrm{bp}$ ) and selected for G418 resistance. The region corresponding to the $\mathrm{N}$-terminal region of the protein was sequence verified. The yeast strain used for transformation was previously mutated (tor 1-1 mutation and FPR1 deletion) to make the cells resistant to rapamycin, while Rpl13a was tagged with FKBP12, as described [24]. BrdU-inc strains were constructed using p405-BrdU-Inc as reported [68]. For MAT-inc strains used in Figs 5A, 5B and S2C and S2D, MAT $\alpha$ sequence was mutated at HO cut site and then inserted to the HIS3 locus using $U R A 3$ selection. Yeast growth/sensitivities by serial dilution spot assays and flow cytometry analysis of cell cycle were performed as before [5].

\section{Chromatin immunoprecipitations (ChIP)}

ChIP-qPCR was performed essentially as reported previously [5] except for the following modifications. For experiments using esa1-L254P mutant, since cells tend to accumulate in G2/M [11], cells were synchronized in G2/M before induction of $\mathrm{HO}$ with galactose (to avoid potentially differed cell cycle population between WT and mutant). More specifically, cells were grown overnight in YPR at $23^{\circ} \mathrm{C}$ until OD600 around 0.5 . Nocodazole was then added $(20 \mu \mathrm{g} / \mathrm{ml}$ final in $1 \%$ DMSO) and cell culture was shifted to $32^{\circ} \mathrm{C}$ for $3 \mathrm{hrs}$ before addition of $2 \%$ galactose for another $3 \mathrm{hrs}$ at $32^{\circ} \mathrm{C}$. Cells were cultured at $30^{\circ} \mathrm{C}$ for all the other ChIP-qPCR experiments performed. For experiments with anchor-away system, cells were grown overnight in YPR until OD600 around 0.5 , and rapamycin was added to a final concentration of $1 \mathrm{ug} / \mathrm{ml}$ for $20 \mathrm{~min}$ followed by $2 \%$ final galactose induction for $3 \mathrm{hrs}$. For experiment with BrdU, cells were grown overnight in YPR until OD600 around 0.5 and then BrdU was added $(400 \mu \mathrm{g} / \mathrm{ml}$ final) and grown for $6 \mathrm{hrs}$. $\mathrm{HO}$ cleavage efficiency was calculated with the ratio from qPCR using primers across the DSB site over an uncut control locus (interV, long intergenic region on chromosome $\mathrm{V}$ ). Lists of primers standardised on a LightCycler qPCR apparatus are available upon request. Antibodies used were against penta-H4 acetylation (Upstate, 06-946), H4 (Abcam, Ab7311), H2B (Abcam, Ab1790), Myc (9E10), Rad51 (SCBT, sc-33626), BrdU (GE, RPN202), Eaf1 [12], Swi2/Snf6, Sth1/ Rsc6 and Rvb1 (kindly provided by Joe Reese, Brad Cairns and Yasutaka Makino, respectively). ChIP-qPCR data are presented as \% of IP/input (or ratio of IP/input when correcting for nucleosome occupancy, i.e. $\mathrm{H} 4 \mathrm{ac} / \mathrm{H} 3, \mathrm{H} 2 \mathrm{~B}$ or $\mathrm{H} 4$ ) and are from at least two independent yeast cultures in each experiment. Anti-Rfal ChIP-coupled to mass spectrometry was described in [5].

\section{Plasmid-based NHEJ assay}

Plasmid-based NHEJ assay was performed essentially as described previously [69]. After transformed with cut or uncut plasmid, cells were plated on URA- plates containing $1 \mu \mathrm{g} / \mathrm{ml} \mathrm{rapa-}$ mycin and let grow around 3 days before the colony numbers were quantified. LEU2 ORF was completely removed from HHY168 genome to prevent potential repair through HR.

\section{Acetyl-lysine IP}

Immunoprecipitation with acetyl-lysine antibody was performed essentially as described previously [5]. Cells were grown in YPD until OD600 around 0.5 followed by addition of rapamycin (lug/ml final) and DMSO or MMS (0.05\% final) for $3 \mathrm{hrs}$. Antibody used were acetyllysine (ImmuneChem, ICP0380), RPA (Agrisera, AS 07-214) and Pgk1 (Abcam, ab113687).

\section{DR-GFP HR assay}

DR-GFP HR assay was performed with DR-GFP-integrated U2OS cells, essentially as reported previously [20]. Knockdown (KD) was carried out with siRNA transfection using 
Lipofectamine RNAimax (ThermoFisher, 13778075) following manufacture's instruction. siTip60 was a single siRNA from the reported Smartpool siRNA pool [20] and validated for KD efficiency (slightly weaker KD than the Smartpool). siGcn5 and siPCAF used were as reported previously [45]. Specific sequences of siRNA are available upon request.

\section{Key points}

- NuA4-dependent acetylation modulates nucleosome dynamics to assist DNA end resection and strand invasion during homologous recombination.

- Combined recruitment and local action of NuA4 and SAGA acetyltransferase complexes is essential for DNA end resection.

- Cooperation between NuA4 and SAGA acetyltransferases is required for homologous recombination in eukaryotes.

\section{Supporting information}

S1 Fig. Using NuA4 mutants in the Gal-HO system to study DSB repair. Related to Fig 1. A) Percentage of $\mathrm{HO}$ cutting efficiency in WT and esa1-L254P mutant after $2 \mathrm{hr} 37^{\circ} \mathrm{C}$ treatment followed by $3 \mathrm{hr}$ galactose induction at $37^{\circ} \mathrm{C}$. B) Western blot (WB) of whole cell extract (WCE) from WT and esa1-L254P cells treated with $23^{\circ} \mathrm{C}$ or $32^{\circ} \mathrm{C}$ for $3 \mathrm{hr}$. Antibodies used are penta-H4 acetylation (Upstate, 06-946) and $\mathrm{H} 4$ (Abcam, Ab7311). C) Percentage of HO cutting efficiency in WT and esa1-L254P cells after $3 \mathrm{hr}$ galactose induction at $32^{\circ} \mathrm{C}$ (based on qPCR across the cut site normalised to control locus). D) ChIP-qPCR of H4ac signal at the $R P S 11 B$ control locus in WT and esa 1 ts strains during galactose induction of HO nuclease, showing no increase (ratio of $\mathrm{H} 4 \mathrm{ac} /$ total $\mathrm{H} 3 \% \mathrm{IP} /$ input, error bars are range of biological replicates). E) Western blot (WB) of $\mathrm{H} 4$ acetylation and $\mathrm{H} 3$ with whole cell extract (WCE) from indicated strains grown in YPD without rapamycin treatment, showing the non-specific effect of Esal tagging at its C-terminus. F) HO cutting efficiency as above in No-FRB and FRB-Esa1 cells after 30min of galactose induction in presence of rapamycin (depleted conditions, no change is seen after $3 \mathrm{hrs}$ either). G) ChIP-qPCR of H4ac signal as above at the RPS11B control locus in No-FRB and FRB-Esa1 strains during galactose induction of $\mathrm{HO}$ nuclease. $\mathrm{H}$ ) Relative H4ac/total H4 level by ChIP-qPCR (ratio of \% IP/input) in No-FRB cells after $3 \mathrm{hr}$ galactose induction in presence of rapamycin. Values at the different locations near the DSB at time 0 was normalized to 1 , showing the increase of $\mathrm{H} 4$ acetylation upon $\mathrm{HO}$ cut. I) Relative $\mathrm{H} 4 \mathrm{ac} /$ total H4 level by ChIP-qPCR (ratio of \% IP/input) in No-FRB and FRB-Esal cells after 3hr galactose induction in presence of rapamycin. Values at the different locations near the DSB in No-FRB cells were normalized to 1, showing the loss of $\mathrm{H} 4$ acetylation induction in FRB-Esa1 cells. J) Relative total H4 level (nucleosome occupancy) by ChIP-qPCR in No-FRB and FRB-Esal cells after 0 and $3 \mathrm{hr}$ galactose induction in presence of rapamycin. $t=0$ values of respective strains were normalized to 1 to show the loss of nucleosomes upon DSB induction, which is less important after depletion of Esal. Error bars represent range from biological duplicates. K-L) BrdU assay validation for measurement of end resection. K) Dot blot of 
BrdU-incorporation strains (BrdU-inc + ) or non-modified strains (BrdU-inc -) grown in YPD without $(\mathrm{BrdU}-)$ or with $(\mathrm{BrdU}+) 400 \mu \mathrm{g} / \mathrm{ml} \mathrm{BrdU}$ for $4 \mathrm{hrs}$. Genomic DNA was spotted on Amersham Hybond-N+ membrane and blotted with BrdU antibody (GE, RPN202). L) ChIP assay of BrdU (\%IP/input) in No-FRB strain after 0 (No damage) or 3hr (+damage) galactose induction, showing clear detection of ssDNA generated by resection within $3 \mathrm{~kb}$ of the $\mathrm{HO}$ break with background signal at 10kb and control locus and in cells not incubated with BrdU (no BrdU).

(TIF)

S2 Fig. NuA4 esa1 mutant or depletion through Eaf1 does not affect NHEJ and HR in reporter assays measuring growth on plates. Related to Figs 2 and 3. A) Plasmid-based NHEJ assay using indicated strains transformed with cut or uncut plasmids, plated on $1 \mu \mathrm{g} / \mathrm{ml}$ rapamycin-containing SCSM-URA solid medium and grown at $30^{\circ} \mathrm{C}$. Error bars represent standard errors from biological triplicates. B) 10 -fold serial dilutions of indicated strains spotted on solid medium without or with indicated amounts of MMS and grown at $32^{\circ} \mathrm{C}$, showing synthetic sickness/interaction between esa1 ts mutant and fun30 deletion. C-D) 10-fold serial dilutions of indicated strains were spotted on YPD or YP containing $2 \%$ galactose to induce $\mathrm{HO}$ break and recombination with the mat-inc donor locus (measured by survival, see system schematic in Fig 5A). The esal ts mutant shows no defect in $\mathrm{HR}$ at $32^{\circ} \mathrm{C}$ ( rad52 deletion is used as positive control) (C). The Eaf1-FRB strain does not show $\mathrm{HR}$ defect either in presence of $1 \mu \mathrm{g} / \mathrm{ml}$ rapamycin grown at $30^{\circ} \mathrm{C}(\mathrm{D})$. (TIF)

S3 Fig. Effects of anchor-away depletion of Esa1, Gcn5 and Esa1/Gcn5 together. Related to Fig 4. A) Western blot analysis of bulk histone acetylation marks in No-FRB, FRB-Esal, Gcn5-FRB and FRB-Esa1/Gcn5-FRB cells after 0, 60, 120, 180 and 240min in Galactose to induce the $\mathrm{HO}$ break as well as in the presence of rapamycin (added 20min before time 0 of galactose). A no rapamycin control before galactose is also shown. Esal depletion shows rapid loss of H4ac (penta) while Gcn 5 depletion shows a decrease of H3ac, most notably H3K27ac. B) Percentage of HO cutting efficiency in No-FRB, FRB-Esa1, Gcn5-FRB and FRB-Esa1/ Gcn5-FRB strains after 30min of induction in galactose. Error bars represent standard error from biological triplicates. Error bars represent standard errors from biological triplicates. C-D) Cell cycle analysis of cells from the same indicated strains by cell cytometry after fixing and staining with PI, before (C) and after 3 hr induction of $\mathrm{HO}$ (D) in presence of rapamycin, showing no major changes in cell cycle profiles between strains and conditions. Error bars represent range from biological duplicates. E) ChIP-qPCR of H4ac signal (ratio of H4ac/total H4\%IP/input) next to the HO break in No-FRB, FRB-Esa1 and FRB-Esa1/Gcn5-FRB strains after $3 \mathrm{hr}$ of galactose induction of $\mathrm{HO}$ in presence of rapamycin, showing the expected loss of H4ac. F) ChIP-qPCR of relative $\mathrm{H} 4$ level (nucleosome occupancy) in the indicated strains after $3 \mathrm{hr}$ galactose induction in presence of rapamycin. Values (\% IP/input) near the HO break were compared to the No-FRB samples set to 1, showing an increase in Esa1/Gcn5-depeleted cells. Arp4-FRB is shown as control as it is a shared subunit not only of NuA4 but also INO80/ SWR1 chromatin remodeling complexes. Error bars represent range from biological duplicates.

S4 Fig. The ATM/ATR-related Tra1 subunit shared by NuA4 and SAGA affects DSB repair but does not recapitulate combined Esa1/Gcn5 function. Related to Figs 4 and 5. A) 10-fold serial dilutions of indicated FRB-tagged strains were spotted on solid medium without or with $1 \mu \mathrm{g} / \mathrm{ml}$ rapamycin supplemented without or with $0.03 \% \mathrm{MMS}$ and grown at $30^{\circ} \mathrm{C}$. Depletion 
of the Tra1 subunit shared by NuA4 and SAGA leads to much decreased viability, while not as much as Esa1/Rpo21, but also clear sensitivity to DNA damage. B) Percentage of HO cutting efficiency in No-FRB and FRB-Tra1 strains after 30min of induction in galactose. Error bars represent standard error from biological triplicates. C-D) ChIP-qPCR assay of Rfa1-13myc (C) and Rad51 (D) (\% of IP/input at different locations around the HO DSB) in No-FRB and FRB-Tral strains after $3 \mathrm{hr}$ of galactose induction. Error bars represent range from biological duplicates.

S5 Fig. Knockdown of PCAF accumulates cells in S/G2. Related to Fig 5D. A) DR-GFP as in Fig 5D with indicated siRNAs. B) Cell cycle analysis of cells shown in (A) and Fig 5D by cell cytometry after fixing and staining cells with PI. Error bars represent range from biological duplicates. Note that siPCAF cells show accumulation in S/G2, potentially accounting for elevated $\mathrm{HR}$ repair efficiency observed in these cells.

S1 Table. Yeast strains used in this study. (DOCX)

\section{Acknowledgments}

We thank Jean-Phillippe Côté for technical assistance. We are very grateful to Joe Reese for providing Swi2 and Snf6 antibodies, Bradley Cairns for Sth1 and Rsc6 antibodies, and François Robert, Lorraine Symington and Susan Gasser for sharing yeast strains.

\section{Author Contributions}

Conceptualization: Xue Cheng, Jacques Côté.

Data curation: Xue Cheng, Valérie Côté.

Formal analysis: Xue Cheng, Valérie Côté, Jacques Côté.

Funding acquisition: Jacques Côté.

Investigation: Xue Cheng, Valérie Côté.

Methodology: Xue Cheng.

Project administration: Jacques Côté.

Supervision: Jacques Côté.

Validation: Jacques Côté.

Writing - original draft: Xue Cheng, Jacques Côté.

Writing - review \& editing: Jacques Côté.

\section{References}

1. Polo SE, Jackson SP. Dynamics of DNA damage response proteins at DNA breaks: a focus on protein modifications. Genes \& development. 2011; 25(5):409-33. Epub 2011/03/03. https://doi.org/10.1101/ gad.2021311 PMID: 21363960; PubMed Central PMCID: PMC3049283.

2. Hustedt N, Durocher D. The control of DNA repair by the cell cycle. Nature cell biology. 2016; 19(1):1-9. Epub 2016/12/23. https://doi.org/10.1038/ncb3452 PMID: 28008184.

3. Jeggo PA, Downs JA, Gasser SM. Chromatin modifiers and remodellers in DNA repair and signalling. Philosophical transactions of the Royal Society of London Series B, Biological sciences. 2017; 372 (1731). Epub 2017/08/30. https://doi.org/10.1098/rstb.2016.0279 PMID: 28847816; PubMed Central PMCID: PMC5577457. 
4. Rother MB, van Attikum $\mathrm{H}$. DNA repair goes hip-hop: SMARCA and CHD chromatin remodellers join the break dance. Philosophical transactions of the Royal Society of London Series B, Biological sciences. 2017; 372(1731). Epub 2017/08/30. https://doi.org/10.1098/rstb.2016.0285 PMID: 28847822; PubMed Central PMCID: PMC5577463.

5. Cheng X, Jobin-Robitaille O, Billon P, Buisson R, Niu H, Lacoste N, et al. Phospho-dependent recruitment of the yeast NuA4 acetyltransferase complex by MRX at DNA breaks regulates RPA dynamics during resection. Proceedings of the National Academy of Sciences of the United States of America. 2018; 115(40):10028-33. Epub 2018/09/19. https://doi.org/10.1073/pnas.1806513115 PMID: 30224481; PubMed Central PMCID: PMC6176631.

6. Downs JA, Allard S, Jobin-Robitaille O, Javaheri A, Auger A, Bouchard N, et al. Binding of chromatinmodifying activities to phosphorylated histone H2A at DNA damage sites. Molecular cell. 2004; 16 (6):979-90. Epub 2004/12/22. https://doi.org/10.1016/j.molcel.2004.12.003 PMID: 15610740.

7. Lin YY, Qi Y, Lu JY, Pan X, Yuan DS, Zhao Y, et al. A comprehensive synthetic genetic interaction network governing yeast histone acetylation and deacetylation. Genes \& development. 2008; 22 (15):2062-74. Epub 2008/08/05. https://doi.org/10.1101/gad.1679508 PMID: 18676811; PubMed Central PMCID: PMC2492751.

8. Bird AW, Yu DY, Pray-Grant MG, Qiu Q, Harmon KE, Megee PC, et al. Acetylation of histone H4 by Esa1 is required for DNA double-strand break repair. Nature. 2002; 419(6905):411-5. Epub 2002/09/ 28. https://doi.org/10.1038/nature01035 PMID: 12353039.

9. Torres-Machorro AL, Aris JP, Pillus L. A moonlighting metabolic protein influences repair at DNA double-stranded breaks. Nucleic acids research. 2015; 43(3):1646-58. Epub 2015/01/30. https://doi.org/ 10.1093/nar/gku1405 PMID: 25628362; PubMed Central PMCID: PMC4330366.

10. Steunou A-L, Rossetto D, Côté J. Regulating Chromatin by Histone Acetylation. In: Workman JL, Abmayr SM, editors. Fundamentals of Chromatin: Springer New York; 2014. p. 147-212. https://doi. org/10.15252/embj.201386433 PMID: 24843044

11. Clarke AS, Lowell JE, Jacobson SJ, Pillus L. Esa1p is an essential histone acetyltransferase required for cell cycle progression. Molecular and cellular biology. 1999; 19(4):2515-26. Epub 1999/03/19. https://doi.org/10.1128/MCB.19.4.2515 PMID: 10082517; PubMed Central PMCID: PMC84044.

12. Auger A, Galarneau L, Altaf M, Nourani A, Doyon Y, Utley RT, et al. Eaf1 is the platform for NuA4 molecular assembly that evolutionarily links chromatin acetylation to ATP-dependent exchange of histone H2A variants. Molecular and cellular biology. 2008; 28(7):2257-70. Epub 2008/01/24. https://doi.org/ 10.1128/MCB.01755-07 PMID: 18212047; PubMed Central PMCID: PMC2268442.

13. Choy JS, Kron SJ. NuA4 subunit Yng2 function in intra-S-phase DNA damage response. Molecular and cellular biology. 2002; 22(23):8215-25. Epub 2002/11/06. https://doi.org/10.1128/MCB.22.23.82158225.2002 PMID: 12417725; PubMed Central PMCID: PMC134065.

14. Bennett $\mathrm{G}$, Papamichos-Chronakis $\mathrm{M}$, Peterson CL. DNA repair choice defines a common pathway for recruitment of chromatin regulators. Nature communications. 2013; 4:2084. Epub 2013/07/03. https:// doi.org/10.1038/ncomms3084 PMID: 23811932; PubMed Central PMCID: PMC3731036.

15. Bennett G, Peterson CL. SWI/SNF recruitment to a DNA double-strand break by the NuA4 and Gcn5 histone acetyltransferases. DNA repair. 2015; 30:38-45. Epub 2015/04/15. https://doi.org/10.1016/j. dnarep.2015.03.006 PMID: 25869823; PubMed Central PMCID: PMC4425604.

16. Renaud-Young M, Lloyd DC, Chatfield-Reed K, George I, Chua G, Cobb J. The NuA4 complex promotes translesion synthesis (TLS)-mediated DNA damage tolerance. Genetics. 2015; 199(4):1065-76. Epub 2015/02/24. https://doi.org/10.1534/genetics.115.174490 PMID: 25701288; PubMed Central PMCID: PMC4391564.

17. House NCM, Yang JH, Walsh SC, Moy JM, Freudenreich $\mathrm{CH}$. NuA4 initiates dynamic histone H4 acetylation to promote high-fidelity sister chromatid recombination at postreplication gaps. Molecular cell. 2014; 55(6):818-28. Epub 2014/08/19. https://doi.org/10.1016/j.molcel.2014.07.007 PMID: 25132173; PubMed Central PMCID: PMC4169719.

18. Hodges AJ, Plummer DA, Wyrick JJ. NuA4 acetyltransferase is required for efficient nucleotide excision repair in yeast. DNA repair. 2018. Epub 2018/11/27. https://doi.org/10.1016/j.dnarep.2018.11.006 PMID: 30473425.

19. Waters $R$, van Eijk $P$, Reed $S$. Histone modification and chromatin remodeling during NER. DNA repair. 2015; 36:105-13. Epub 2015/10/01. https://doi.org/10.1016/j.dnarep.2015.09.013 PMID: 26422133.

20. Jacquet K, Fradet-Turcotte A, Avvakumov N, Lambert JP, Roques C, Pandita RK, et al. The TIP60 Complex Regulates Bivalent Chromatin Recognition by 53BP1 through Direct H4K20me Binding and H2AK15 Acetylation. Molecular cell. 2016; 62(3):409-21. Epub 2016/05/08. https://doi.org/10.1016/j. molcel.2016.03.031 PMID: 27153538; PubMed Central PMCID: PMC4887106. 
21. Murr R, Loizou JI, Yang YG, Cuenin C, Li H, Wang ZQ, et al. Histone acetylation by Trrap-Tip60 modulates loading of repair proteins and repair of DNA double-strand breaks. Nature cell biology. 2006; 8 (1):91-9. Epub 2005/12/13. https://doi.org/10.1038/ncb1343 PMID: 16341205.

22. Tang J, Cho NW, Cui G, Manion EM, Shanbhag NM, Botuyan MV, et al. Acetylation limits 53BP1 association with damaged chromatin to promote homologous recombination. Nature structural \& molecular biology. 2013; 20(3):317-25. Epub 2013/02/05. https://doi.org/10.1038/nsmb.2499 PMID: 23377543; PubMed Central PMCID: PMC3594358.

23. Lee SE, Moore JK, Holmes A, Umezu K, Kolodner RD, Haber JE. Saccharomyces Ku70, mre11/rad50 and RPA proteins regulate adaptation to G2/M arrest after DNA damage. Cell. 1998; 94(3):399-409. Epub 1998/08/26. https://doi.org/10.1016/s0092-8674(00)81482-8 PMID: 9708741.

24. Haruki H, Nishikawa J, Laemmli UK. The anchor-away technique: rapid, conditional establishment of yeast mutant phenotypes. Molecular cell. 2008; 31(6):925-32. Epub 2008/10/17. https://doi.org/10. 1016/j.molcel.2008.07.020 PMID: 18922474.

25. Zentner GE, Tsukiyama T, Henikoff S. ISWI and CHD chromatin remodelers bind promoters but act in gene bodies. PLoS genetics. 2013; 9(2):e1003317. Epub 2013/03/08. https://doi.org/10.1371/journal. pgen.1003317 PMID: 23468649; PubMed Central PMCID: PMC3585014.

26. Chen H, Symington LS. Overcoming the chromatin barrier to end resection. Cell research. 2013; 23 (3):317-9. Epub 2012/11/14. https://doi.org/10.1038/cr.2012.148 PMID: 23147792; PubMed Central PMCID: PMC3587700.

27. Chen X, Cui D, Papusha A, Zhang X, Chu CD, Tang J, et al. The Fun30 nucleosome remodeller promotes resection of DNA double-strand break ends. Nature. 2012; 489(7417):576-80. Epub 2012/09/ 11. https://doi.org/10.1038/nature11355 PMID: 22960743; PubMed Central PMCID: PMC3640768.

28. Costelloe T, Louge R, Tomimatsu N, Mukherjee B, Martini E, Khadaroo B, et al. The yeast Fun30 and human SMARCAD1 chromatin remodellers promote DNA end resection. Nature. 2012; 489 (7417):581-4. Epub 2012/09/11. https://doi.org/10.1038/nature11353 PMID: 22960744; PubMed Central PMCID: PMC3493121.

29. Tsukuda T, Fleming AB, Nickoloff JA, Osley MA. Chromatin remodelling at a DNA double-strand break site in Saccharomyces cerevisiae. Nature. 2005; 438(7066):379-83. Epub 2005/11/18. https://doi.org/ 10.1038/nature04148 PMID: 16292314; PubMed Central PMCID: PMC1388271.

30. Wiest NE, Houghtaling S, Sanchez JC, Tomkinson AE, Osley MA. The SWI/SNF ATP-dependent nucleosome remodeler promotes resection initiation at a DNA double-strand break in yeast. Nucleic acids research. 2017; 45(10):5887-900. Epub 2017/04/12. https://doi.org/10.1093/nar/gkx221 PMID: 28398510 ; PubMed Central PMCID: PMC5449591.

31. Symington LS. Mechanism and regulation of DNA end resection in eukaryotes. Critical reviews in biochemistry and molecular biology. 2016; 51(3):195-212. Epub 2016/04/22. https://doi.org/10.3109/ 10409238.2016.1172552 PMID: 27098756; PubMed Central PMCID: PMC4957645.

32. Renkawitz J, Lademann CA, Kalocsay M, Jentsch S. Monitoring homology search during DNA doublestrand break repair in vivo. Molecular cell. 2013; 50(2):261-72. Epub 2013/03/26. https://doi.org/10. 1016/j.molcel.2013.02.020 PMID: 23523370.

33. van Attikum H, Fritsch O, Gasser SM. Distinct roles for SWR1 and INO80 chromatin remodeling complexes at chromosomal double-strand breaks. The EMBO journal. 2007; 26(18):4113-25. Epub 2007/ 09/01. https://doi.org/10.1038/sj.emboj.7601835 PMID: 17762868; PubMed Central PMCID: PMC2230671.

34. Westmoreland JW, Resnick MA. Coincident resection at both ends of random, gamma-induced doublestrand breaks requires MRX (MRN), Sae2 (Ctp1), and Mre11-nuclease. PLoS genetics. 2013; 9(3): e1003420. Epub 2013/04/05. https://doi.org/10.1371/journal.pgen.1003420 PMID: 23555316; PubMed Central PMCID: PMC3610664.

35. Durant M, Pugh BF. Genome-wide relationships between TAF1 and histone acetyltransferases in Saccharomyces cerevisiae. Molecular and cellular biology. 2006; 26(7):2791-802. Epub 2006/03/16. https://doi.org/10.1128/MCB.26.7.2791-2802.2006 PMID: 16537921; PubMed Central PMCID: PMC1430310.

36. Bruzzone MJ, Grunberg S, Kubik S, Zentner GE, Shore D. Distinct patterns of histone acetyltransferase and Mediator deployment at yeast protein-coding genes. Genes \& development. 2018; 32(1718):1252-65. Epub 2018/08/16. https://doi.org/10.1101/gad.312173.118 PMID: 30108132; PubMed Central PMCID: PMC6120713.

37. Ginsburg DS, Govind CK, Hinnebusch AG. NuA4 lysine acetyltransferase Esa1 is targeted to coding regions and stimulates transcription elongation with Gcn5. Molecular and cellular biology. 2009; 29 (24):6473-87. Epub 2009/10/14. https://doi.org/10.1128/MCB.01033-09 PMID: 19822662; PubMed Central PMCID: PMC2786879. 
38. Downey M, Johnson JR, Davey NE, Newton BW, Johnson TL, Galaang S, et al. Acetylome profiling reveals overlap in the regulation of diverse processes by sirtuins, gcn5, and esa1. Molecular \& cellular proteomics: MCP. 2015; 14(1):162-76. Epub 2014/11/09. https://doi.org/10.1074/mcp.M114.043141 PMID: 25381059; PubMed Central PMCID: PMC4288252.

39. He H, Wang J, Liu T. UV-Induced RPA1 Acetylation Promotes Nucleotide Excision Repair. Cell reports. 2017; 20(9):2010-25. Epub 2017/08/31. https://doi.org/10.1016/j.celrep.2017.08.016 PMID: 28854355.

40. Robert T, Vanoli F, Chiolo I, Shubassi G, Bernstein KA, Rothstein R, et al. HDACs link the DNA damage response, processing of double-strand breaks and autophagy. Nature. 2011; 471(7336):74-9. Epub 2011/03/04. https://doi.org/10.1038/nature09803 PMID: 21368826; PubMed Central PMCID: PMC3935290.

41. Zhao M, Geng R, Guo X, Yuan R, Zhou X, Zhong Y, et al. PCAF/GCN5-Mediated Acetylation of RPA1 Promotes Nucleotide Excision Repair. Cell reports. 2017; 20(9):1997-2009. Epub 2017/08/31. https:// doi.org/10.1016/j.celrep.2017.08.015 PMID: 28854354.

42. Brown CE, Howe L, Sousa K, Alley SC, Carrozza MJ, Tan S, et al. Recruitment of HAT complexes by direct activator interactions with the ATM-related Tra1 subunit. Science. 2001; 292(5525):2333-7. Epub 2001/06/26. https://doi.org/10.1126/science.1060214 PMID: 11423663.

43. Wu PY, Winston F. Analysis of Spt7 function in the Saccharomyces cerevisiae SAGA coactivator complex. Molecular and cellular biology. 2002; 22(15):5367-79. Epub 2002/07/09. https://doi.org/10.1128/ MCB.22.15.5367-5379.2002 PMID: 12101232; PubMed Central PMCID: PMC133947.

44. Mantiero D, Clerici M, Lucchini G, Longhese MP. Dual role for Saccharomyces cerevisiae Tel1 in the checkpoint response to double-strand breaks. EMBO reports. 2007; 8(4):380-7. Epub 2007/03/10. https://doi.org/10.1038/sj.embor.7400911 PMID: 17347674; PubMed Central PMCID: PMC1852765.

45. Clouaire T, Rocher V, Lashgari A, Arnould C, Aguirrebengoa M, Biernacka A, et al. Comprehensive Mapping of Histone Modifications at DNA Double-Strand Breaks Deciphers Repair Pathway Chromatin Signatures. Molecular cell. 2018; 72(2):250-62 e6. Epub 2018/10/03. https://doi.org/10.1016/j.molcel. 2018.08.020 PMID: 30270107; PubMed Central PMCID: PMC6202423.

46. Delamarre A, Barthe A, de la Roche Saint-Andre C, Luciano P, Forey R, Padioleau I, et al. MRX Increases Chromatin Accessibility at Stalled Replication Forks to Promote Nascent DNA Resection and Cohesin Loading. Molecular cell. 2020; 77(2):395-410 e3. Epub 2019/11/25. https://doi.org/10.1016/j. molcel.2019.10.029 PMID: 31759824.

47. Hassan AH, Neely KE, Workman JL. Histone acetyltransferase complexes stabilize swi/snf binding to promoter nucleosomes. Cell. 2001; 104(6):817-27. Epub 2001/04/06. https://doi.org/10.1016/s00928674(01)00279-3 PMID: 11290320.

48. Hassan AH, Prochasson P, Neely KE, Galasinski SC, Chandy M, Carrozza MJ, et al. Function and selectivity of bromodomains in anchoring chromatin-modifying complexes to promoter nucleosomes. Cell. 2002; 111(3):369-79. Epub 2002/11/07. https://doi.org/10.1016/s0092-8674(02)01005-x PMID: 12419247.

49. Carey M, Li B, Workman JL. RSC exploits histone acetylation to abrogate the nucleosomal block to RNA polymerase II elongation. Molecular cell. 2006; 24(3):481-7. Epub 2006/11/04. https://doi.org/10. 1016/j.molcel.2006.09.012 PMID: 17081996; PubMed Central PMCID: PMC1847601.

50. Seeber A, Hauer M, Gasser SM. Nucleosome remodelers in double-strand break repair. Current opinion in genetics \& development. 2013; 23(2):174-84. Epub 2013/01/29. https://doi.org/10.1016/j.gde. 2012.12.008 PMID: 23352131.

51. Peritore M, Reusswig KU, Bantele SCS, Straub T, Pfander B. Strand-specific ChIP-seq at DNA breaks distinguishes ssDNA versus dsDNA binding and refutes single-stranded nucleosomes. Molecular cell. 2021; 81(8):1841-53 e4. Epub 2021/03/03. https://doi.org/10.1016/j.molcel.2021.02.005 PMID: 33651987.

52. Chai B, Huang J, Cairns BR, Laurent BC. Distinct roles for the RSC and Swi/Snf ATP-dependent chromatin remodelers in DNA double-strand break repair. Genes \& development. 2005; 19(14):1656-61. Epub 2005/07/19. https://doi.org/10.1101/gad.1273105 PMID: 16024655; PubMed Central PMCID: PMC1176001.

53. Kent NA, Chambers AL, Downs JA. Dual chromatin remodeling roles for RSC during DNA double strand break induction and repair at the yeast MAT locus. The Journal of biological chemistry. 2007; 282 (38):27693-701. Epub 2007/07/27. https://doi.org/10.1074/jbc.M704707200 PMID: 17652077.

54. Lademann CA, Renkawitz J, Pfander B, Jentsch S. The INO80 Complex Removes H2A.Z to Promote Presynaptic Filament Formation during Homologous Recombination. Cell reports. 2017; 19(7):1294303. Epub 2017/05/18. https://doi.org/10.1016/j.celrep.2017.04.051 PMID: 28514650.

55. Sharma S, Anand R, Zhang X, Francia S, Michelini F, Galbiati A, et al. MRE11-RAD50-NBS1 Complex Is Sufficient to Promote Transcription by RNA Polymerase II at Double-Strand Breaks by Melting DNA 
Ends. Cell reports. 2021; 34(1):108565. Epub 2021/01/07. https://doi.org/10.1016/j.celrep.2020. 108565 PMID: 33406426; PubMed Central PMCID: PMC7788559.

56. Liu S, Hua Y, Wang J, Li L, Yuan J, Zhang B, et al. RNA polymerase III is required for the repair of DNA double-strand breaks by homologous recombination. Cell. 2021; 184(5):1314-29 e10. Epub 2021/02/ 25. https://doi.org/10.1016/j.cell.2021.01.048 PMID: 33626331.

57. Yasuhara T, Kato R, Hagiwara Y, Shiotani B, Yamauchi M, Nakada S, et al. Human Rad52 Promotes XPG-Mediated R-loop Processing to Initiate Transcription-Associated Homologous Recombination Repair. Cell. 2018; 175(2):558-70 e11. Epub 2018/09/25. https://doi.org/10.1016/j.cell.2018.08.056 PMID: 30245011.

58. Deng SK, Gibb B, de Almeida MJ, Greene EC, Symington LS. RPA antagonizes microhomology-mediated repair of DNA double-strand breaks. Nature structural \& molecular biology. 2014; 21(4):405-12. Epub 2014/03/13. https://doi.org/10.1038/nsmb.2786 PMID: 24608368; PubMed Central PMCID: РMC3980576.

59. Taty-Taty GC, Chailleux C, Quaranta M, So A, Guirouilh-Barbat J, Lopez BS, et al. Control of alternative end joining by the chromatin remodeler p400 ATPase. Nucleic acids research. 2016; 44(4):1657-68. Epub 2015/11/19. https://doi.org/10.1093/nar/gkv1202 PMID: 26578561; PubMed Central PMCID: PMC4770216.

60. Ye Y, Kirkham-McCarthy L, Lahue RS. The Saccharomyces cerevisiae Mre11-Rad50-Xrs2 complex promotes trinucleotide repeat expansions independently of homologous recombination. DNA repair. 2016; 43:1-8. Epub 2016/05/14. https://doi.org/10.1016/j.dnarep.2016.04.012 PMID: 27173583.

61. Lin YY, Lu JY, Zhang J, Walter W, Dang W, Wan J, et al. Protein acetylation microarray reveals that NuA4 controls key metabolic target regulating gluconeogenesis. Cell. 2009; 136(6):1073-84. Epub 2009/03/24. https://doi.org/10.1016/j.cell.2009.01.033 PMID: 19303850; PubMed Central PMCID: PMC2696288.

62. Jeong J, Juhn K, Lee H, Kim SH, Min BH, Lee KM, et al. SIRT1 promotes DNA repair activity and deacetylation of Ku70. Experimental \& molecular medicine. 2007; 39(1):8-13. Epub 2007/03/06. https://doi. org/10.1038/emm.2007.2 PMID: 17334224.

63. Miller KM, Tjeertes JV, Coates J, Legube G, Polo SE, Britton S, et al. Human HDAC1 and HDAC2 function in the DNA-damage response to promote DNA nonhomologous end-joining. Nature structural \& molecular biology. 2010; 17(9):1144-51. Epub 2010/08/31. https://doi.org/10.1038/nsmb.1899 PMID: 20802485; PubMed Central PMCID: PMC3018776.

64. Wang L, Dent SY. Functions of SAGA in development and disease. Epigenomics. 2014; 6(3):329-39. Epub 2014/08/12. https://doi.org/10.2217/epi.14.22 PMID: 25111486; PubMed Central PMCID: PMC4159956.

65. Gao C, Bourke E, Scobie M, Famme MA, Koolmeister T, Helleday T, et al. Rational design and validation of a Tip60 histone acetyltransferase inhibitor. Scientific reports. 2014; 4:5372. Epub 2014/06/21. https://doi.org/10.1038/srep05372 PMID: 24947938; PubMed Central PMCID: PMC4064327.

66. Clements KE, Schleicher EM, Thakar T, Hale A, Dhoonmoon A, Tolman NJ, et al. Identification of regulators of poly-ADP-ribose polymerase inhibitor response through complementary CRISPR knockout and activation screens. Nature communications. 2020; 11(1):6118. Epub 2020/12/02. https://doi.org/ 10.1038/s41467-020-19961-w PMID: 33257658; PubMed Central PMCID: PMC7704667.

67. Bahler J, Wu JQ, Longtine MS, Shah NG, McKenzie A 3rd, Steever AB, et al. Heterologous modules for efficient and versatile PCR-based gene targeting in Schizosaccharomyces pombe. Yeast. 1998; 14 (10):943-51. Epub 1998/08/26. https://doi.org/10.1002/(SICl)1097-0061(199807)14:10<943::AIDYEA292>3.0.CO;2-Y PMID: 9717240.

68. Viggiani CJ, Aparicio OM. New vectors for simplified construction of BrdU-Incorporating strains of Saccharomyces cerevisiae. Yeast. 2006; 23(14-15):1045-51. Epub 2006/11/04. https://doi.org/10.1002/ yea.1406 PMID: 17083135.

69. Ooi SL, Shoemaker DD, Boeke JD. A DNA microarray-based genetic screen for nonhomologous endjoining mutants in Saccharomyces cerevisiae. Science. 2001; 294(5551):2552-6. Epub 2001/11/10. https://doi.org/10.1126/science.1065672 PMID: 11701889. 